\title{
Epidemiological investigation of caries prevalence in first grade school children in Rhineland-Palatinate, Germany
}

Jens Weusmann ${ }^{1 *}$, Benjamin Mahmoodi ${ }^{1}$, Adriano Azaripour ${ }^{1}$, Kristian Kordsmeyer $^{1}$, Christian Walter ${ }^{2}$ and Brita Willershausen ${ }^{1}$

\begin{abstract}
Introduction: The annual examination of first graders' oral health as stipulated by law aimed to reach every child in Rhineland-Palatinate (Germany) in their first year of school. We intended to evaluate the first graders' oral health based on the examination data for 2013/2014.

Methods: Instructed examiners measured the d3mft(deciduous)/D3MFT(permanent) index according to World Health Organization criteria in 25,020 predominantly 6-7 year-old first-grade school children. Only caries affecting dentin was diagnosed; no radiography or fiber-transillumination was used. Out of the d3mft value, the "Significant Caries Index" (SiC) was calculated. This index identifies the dmft score of the third of the population with the highest caries experience. Descriptive analysis was performed.

Results: Out of the the examined children, $60.9 \%$ were caries free. Mean d3mft score was $1.28 \pm 2.27$ while the mean $\mathrm{SiC}$ was $3.73 \pm 2.51$. A distinctly higher $\mathrm{d} 3 \mathrm{mft}$ was found in the decidous molars compared to the front teeth. Boys were significantly more caries-experienced than girls $(p<0.001)$.

Conclusion: The results of this study confirm the lasting trend towards decreasing caries prevalence in children starting school found in previous cross-sectional studies. This trend was observed in the high-risk group (obtained by $\mathrm{SiC}$ ) as well as in the entire study population. Particular attention in caries prophylaxis should be paid to the primary molars.
\end{abstract}

Keywords: Caries, Childhood, Epidemiology, Dental health, Prophylaxis

\section{Introduction}

Dental caries, as a result of a disturbance of the ecological balance on the dental hard tissues caused by plaque microorganisms [1] is one of the most prevalent diseases in children. Among 5- to 17-year-old Americans, it is more than 5 times as common as reported asthma and 7 times as common as hay fever [2]. In 1981, one of the global goals of the World Health Organization and World Dental Federation was to reach a $50 \%$ caries free dentition in five-and-six year-old children until the year 2000. This aim was, in a global view, achieved widely [3].

\footnotetext{
* Correspondence: jens.weusmann@unimedizin-mainz.de

'Department of Operative Dentistry, University Medical Center of the, Johannes Gutenberg-University Mainz, Augustusplatz 2, 55131 Mainz, Germany

Full list of author information is available at the end of the article
}

In 2003, World Health Organization, World Dental Federation and International Association for Dental Research suggested to consider the specific values "with regard of the political, socio-economic and legislative context" and left the decision about the definite aims to the national level [3]. Thus, the German dental board aims $80 \%$ of the six-year old children in Germany to have a caries free primary dentition in 2020 [4].

Having high caries experience early in life predicts having an increased risk of caries in adulthood [5]. Hence, prevention plays an important role already in childhood [6]. As caries can, depending on the extent, negatively affect the children's ability to eat, sleep, and do schoolwork, therefore, it's effect on the overall aims of children's development should not be underestimated [6]. 
Dental public health promotion programs for kindergartens and schools are legally regulated in Austria and Germany [7]. The German Association for Youth Dental Healthcare coordinates the prevention programs on a national level, while regional branches work together with schools and kindergartens on a local level.

The aim of this study was to examine caries prevalence and experience as well as localisation in first grade school children in the german state of RhinelandPalatinate.

\section{Methods}

Rhineland-Palatinate is a state in the Federal Republic of Germany with approximately four millions inhabitants. Here, within the scope of prevention measures required by law, every year the first grade school children (six and seven years-old) are systematically examined by dentists from the German association for youth dental healthcare. The d3mft/D3MFT index was evaluated.

The dmft/DMFT index has been in use for about 75 years and still remains the most commonly used epidemiological index for assessing dental caries [8]. The letter $\mathrm{d} / \mathrm{D}$ means a decayed tooth, $\mathrm{m} / \mathrm{M}$ a missing tooth extracted due to caries and $\mathrm{f} / \mathrm{F}$ stands for a tooth with an intact filling; lowercase letters were used for the primary and capital letters for the permanent dentition. The $\mathrm{d} 3 \mathrm{mft}$ is a modification that assesses caries only if the decay affects the dentin layer.

To estimate the burden of the high risk groups populations the Significant Caries Index ( $\mathrm{SiC}$ ) first described by Bratthall is used, describing the the mean $\mathrm{dmft}$ of the third of the population with the highest caries experience [9].

The aim of this cross-sectional study was to examine the oral health of all first year elementary school children in the federal state of Rhineland-Palatinate, Germany in 2013/2014 and to analyse the distribution of caries. For this purpose, we aimed to include all available records made by the school dentists in 2013/2014.

A total of 541 school dentists contributed to the findings of this study. The examiners were briefed by a brochure with guidelines concerning caries detection that are based on the WHO criteria. The examinations were conducted between September 2013 and June 2014. Children in 844 primary schools were included in this study.

The examinations took place at school in separate rooms. The children were seated on a normal chair. A disposable mouth mirror was used by default, as well as a standartised lamplight. No radiography or fiber-optic transillumination was used. Dental probing was done if dentin involvement was uncertain only.

Every child was categorised into either "naturally healthy", which was defined as $\mathrm{d} 3 \mathrm{mft}+\mathrm{D} 3 \mathrm{MFT}=0$; "successfully treated/ no need for treatment" what means $\mathrm{F}(\mathrm{T}) / \mathrm{f}(\mathrm{t})>0$ simultaneously to $\mathrm{d} 3 \mathrm{~m}(\mathrm{t}) / \mathrm{D} 3 \mathrm{M}(\mathrm{T})=$ 0 , or "need for treatment", if $\mathrm{d} 3(\mathrm{t}) / \mathrm{D} 3(\mathrm{~T})>0$. An "increased risk of caries" was diagnosed if $\mathrm{d} 3 \mathrm{mft}+$ $\mathrm{D} 3 \mathrm{MFT}>5$ and/or D3(T) $>0$.

The parents had been informed in writing in advance about the screening. Afterwards, they were informed about the results by a letter and, if necessary, suggested to consult a dentist with their child.

Since the examination was not carried out for a primary scientific purpose, no ethical approval was necessary. This was confirmed by a letter from the RhinelandPalatinate ethics committee, dated 05-13-15. All paper screening forms were collected at the RhinelandPalatinate Association for Youth Dental Healthcare and were digitalised anonymously using MS Excel.

Mann-Whitney $\mathrm{U}$ tests (two-sided) were done to compare dmft and $\mathrm{SiC}$ of male and female children; a two-sided chi-square test was conducted to compare the number of male and female children with $\mathrm{dmft}=0$. IBM SPSS 22.00.00 was used for analysing the data. The global level of significance was set at $5 \%$; due to multiple testing the Bonferroni correction was applied. The local level of significance was 0.017 .

\section{Results}

\section{Study population}

According to the governmental data, 32,640 first graders were registered in Rhineland-Palatinate for the school term $2013 / 2014$ in a total of 825 elementary schools. Out of those first graders, 30,376 (93\%) were recorded by the school dentists. 1,854 (5.7 \%) individuals were excluded due to lack of compliance, absence, no parental consent or illegibility of the examination sheets resulting in 28,522 students from 825 schools. For another 3,502, the detailed $\mathrm{d} 3 \mathrm{mft} / \mathrm{D} 3 \mathrm{MFT}$ findings were not available, so that for these analyses only 25,020 subjects were included (Fig. 1).

\section{Oral health evaluation}

$50.9 \%$ of the children were male. The proportion of female children with naturally healthy teeth was $63.5 \%$ compared to $59.2 \%$ in male children.

Since 4,118 first graders were not recorded due to non-participation or illegibility (Fig. 1), the oral health evaluation was available for 28,522 first graders (Table 1). $25.9 \%$ of the children had caries that needed to be treated. Out of those $7.7 \%$ (equaling $1.9 \%$ from the entire population; boys $8.2 \%$, girls $6.7 \%$ ) had an increased caries risk $(\mathrm{d} 3 \mathrm{mft}>5)$.

\section{d3mft, D3MFT and SiC}

From a total of $n=25,020$ individuals, the original examination sheets were evaluable in detail, including $\mathrm{d} 3 \mathrm{mft} /$ 


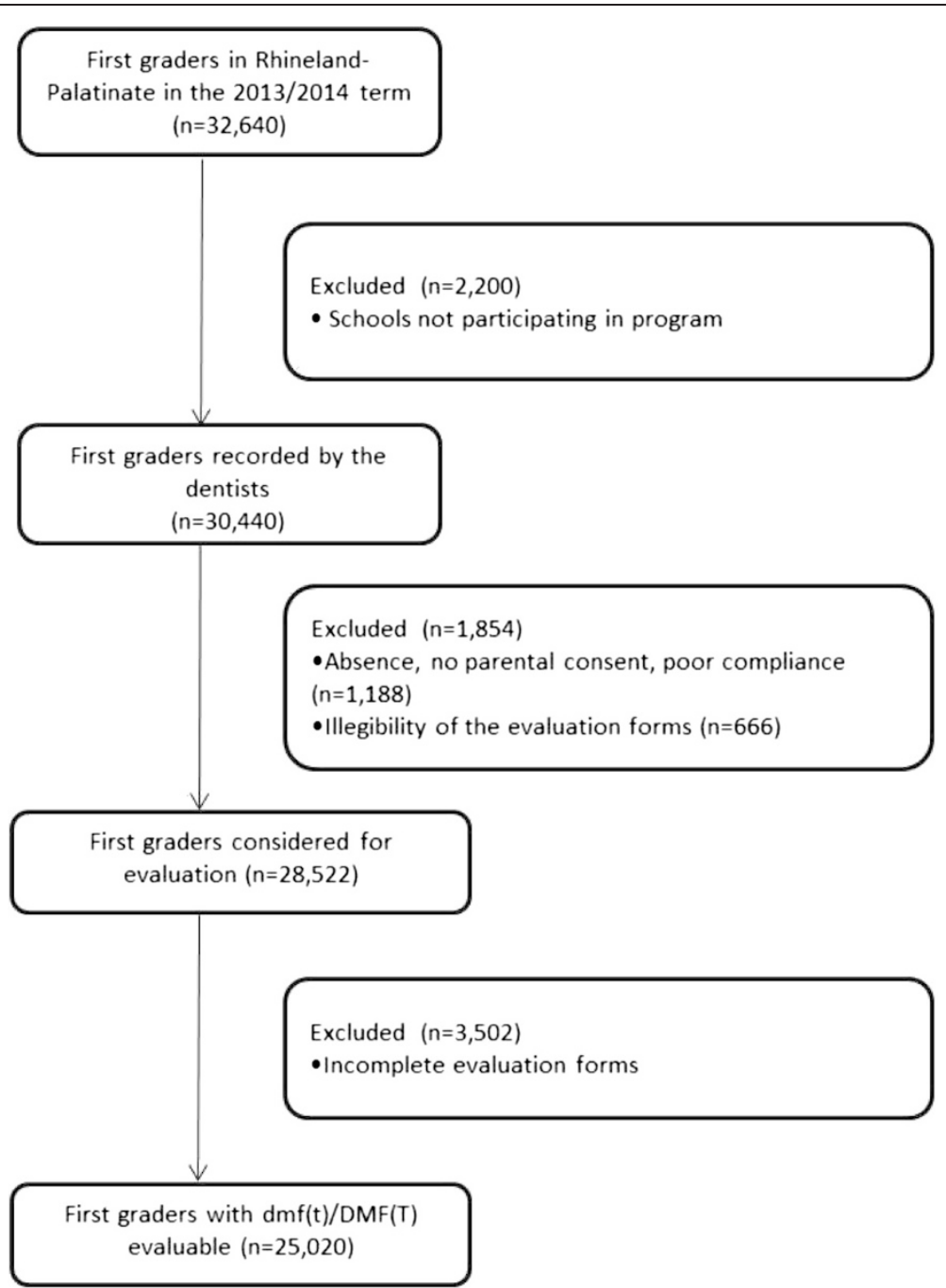

Fig. 1 Study participants flow diagram

D3MFT (Fig. 1). $50.9 \%$ of the children were male, $49.1 \%$ were female.

The mean $\mathrm{d} 3 \mathrm{mft} / \mathrm{D} 3 \mathrm{MFT}$ results are presented in Table 2. Figure 2 shows the distribution of the $\mathrm{d} 3 \mathrm{mft}$ findings with respect to the intra-oral position.

The better overall dental health of girls compared to boys is also seen in the $\mathrm{d} 3 \mathrm{mft}$ distribution. The group of girls with a $\mathrm{d} 3 \mathrm{mft}=0$ was $65.3 \%$ compared to $60.8 \%$ $(p<0.001)$. At the same time, the proportion of boys

Table 1 Oral health estimation of first graders in RhinelandPalatinate in 2013/2014 in percent $(n=28,522)$

\begin{tabular}{lll}
\hline Dental condition & $\%$ & $\mathrm{n}$ \\
\hline Naturally healthy & 60.9 & 17,364 \\
Successfully treated & 13.2 & 3,763 \\
Need for caries treatment & 25.9 & 7,395 \\
Increased Risk of Caries & 7.7 & 2,188 \\
\hline
\end{tabular}

with a d3mft score of 10 or higher with $1.2 \%$ was twice as high as that of girls. Also the mean $\mathrm{d} 3 \mathrm{mft}$ was 1.38 (SD: 2.37, $\mathrm{Q} 1=0$, median $=0, \mathrm{Q} 3=2$ ) compared to 1.15 (SD: $2.12, \mathrm{Q} 1=0$, median $=0, \mathrm{Q} 3=2$ ) was higher among male than among female students $(p<0.001)$, as well as the $\mathrm{SiC}$ (3.97 [SD: 2.58, Q1 $=2$, median $=3, \mathrm{Q} 3=6$ ] vs. 3.41 [SD: 2.40, Q1 = 2, median =3, Q3 = 5] $\quad(\mathrm{p}=0.004)$. The $\mathrm{d} 3 \mathrm{mft}$ ranged from 0 to 20 and the D3MFT from 0 to 6 with a continuous decrease the higher the index was.

Table 2 School children's d3mft/D3MFT and SiC

\begin{tabular}{llllll}
\hline Primary dentition & $d m f(t)$ & $d(t)$ & $m(t)$ & $f(t)$ & $\mathrm{SiC}(\mathrm{dmft})$ \\
& $1.28(\mathrm{SE}: 0.014)$ & 0.71 & 0.17 & 0.41 & 3.73 \\
Permanent dentition & $\mathrm{DMF}(\mathrm{T})$ & $\mathrm{D}(\mathrm{T})$ & $\mathrm{M}(\mathrm{T})$ & $\mathrm{F}(\mathrm{T})$ & $\mathrm{SiC}(\mathrm{DMFT})$ \\
& $0.04(\mathrm{SE}: 0.02)$ & 0.03 & 0.0007 & 0.009 & 0.08
\end{tabular}




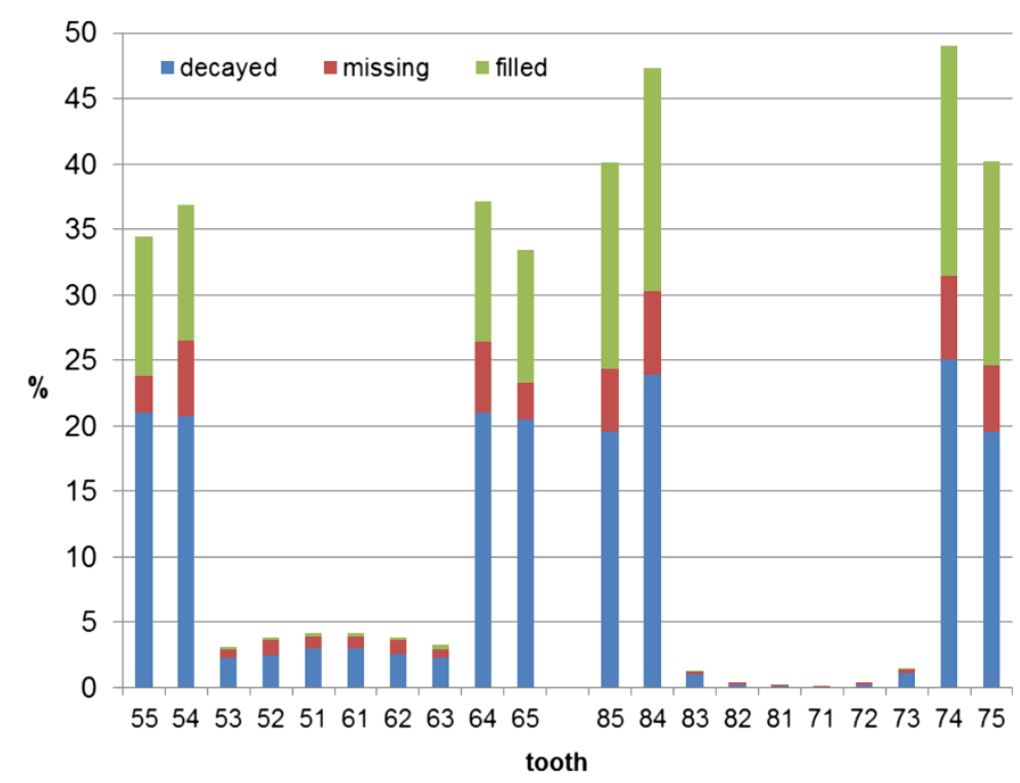

Fig. 2 Distribution of the d3mft index $(n=25,020)$ according to teeth

Only minor variations were seen in children with very high d3mft/D3MFT index (>15). In the present study the state of teeth eruption was not evaluated.

Looking at the location of caries in the deciduous dentition, a clear symmetry and an accumulation in the molar area is obvious (Fig. 2).

\section{Discussion}

The average $\mathrm{d} 3 \mathrm{mft}$ score among first graders in Rhineland-Palatinate in this study was 1.28 with $62.7 \%$ with a caries free primary dentition $(\mathrm{d} 3 \mathrm{mft}=$ 0 ). This confirms a trend towards lower caries prevalence as seen in the last years. The German Association for Youth Dental Healthcare evaluated the $\mathrm{dmft}$ of six-and-seven year-old children in Germany, including Rhineland-Palatinate in the years 1994/1995, 1997, 2000, 2004 and 2009 [7]. In 2009, $55.5 \%$ of the children with a caries free primary dentition [7]. From 1994/1995 until 2009 the mean dmft decreased by $36.4 \%$.

The d3mft of 1.28 of our study reflects another decline of $28.1 \%$ compared to the recent values of RhinelandPalatinate [7] similar to the average $\mathrm{SiC}$ value that decreased 24.8 \% from 4.96 in 2009 to 3.73 in 2014, with the limitation of the differing diagnostic procedure.

Still, no caries assessment method has gained acceptance for international studies. Discrepancies were furthermore to be found in the sample selection compared to the former studies: In the 2009 German Association for Youth Dental Healthcare survey, a $5 \%$ sample $(n=2,096)$ was selected using a two-stage random sampling procedure [7] contrary to our attempt to include all available data.

The aims for caries prevalence in Germany postulated by the German Dental Board aimed $80 \%$ of the six yearold children to be caries free in 2020 [4]. Although this goal seems still far away, the ongoing trend towards lower caries prevalence in first graders is undeniable.

The $\mathrm{d} 3 \mathrm{mft}$ accumulation in the deciduous molars, primarily in the lower jaw is noticeable. Children as well as their parents should call special attention to dental hygiene measures. Causative for that finding could be the motoric deficiencies in an early age, combined with the increased difficulty to keep the posterior interdental spaces clean. Additionally, the lack of visibility compared to the front teeth could be a reason for the neglect. Even though it remains uncertain, whether this is truly a problem of insufficient oral hygiene or caused by other factors such as anatomy, it would be of interest to clearly identify the reason for this finding.

The main limitation of our study is the large number of examiners and the lack of inter-examiner reliability tests. Further limits of the study might be the data acquisition, as well as the slightly differing way of diagnosing caries, since in our study dentin affection was decisive. Usually, the dmft/DMFT score is obtained in a setting without a dental chair with the appropriate light and air syringe. Within the last decades, the use of tooth-coloured restaurations such as compomeres, composites, and modern glass ionomere materials has increased and is part of the dental teaching curricula in many countries [10]. Therefore, tooth-coloured fillings that meet the highest standards of esthetics are more 
difficult to diagnose in a screening situation and could have influenced the results towards a lower dmft score. Unfortunately, no international standard to determine the decay in dmft has been established yet. The range in other studys reaches from "no exact caries definition" over "cavitating lesions" to "caries affecting the dentin layer", as conducted in our study. This, as well as the aspect that caries lesions affecting only enamel were not detected in this study, will have lead to a lower $\mathrm{dmft}$ score.

Nonetheless, with respect to the high number of examiners, "dentin affection" is comparatively easy to reproduce and could have helped to avoid false positive diagnoses.

A more differentiated caries index, as well as measured interexaminer-reliabilities would clearly have a positive influence on the findings' validity. Looking at the high number of first graders and the high number of examiners, the latter postulation will be most difficult to establish. Several field studies used ICDAS as an assessment method [11, 12]. This index provides findings that give a statement about caries quality instead of a sheer yes/no-decision.

In the year 2000, Pistorius et al. independently analysed the dental health of 3,880 first grade school children out of 80 schools in Rheinhessen, a small region of Rhineland-Palatinate within the scope of governmental group prophylaxis [13]. In this study, dental probes were used for caries detection. The average dmft score of 1.9 with a fraction of $53.4 \%$ having a naturally healthy dentition confirms the overall trend between 1994 (39.2\% caries free) up today (62.7\% caries free).

Looking at the permanent dentition, the 2009 study has, with a DMFT score of 0.03 , similar findings to our result of 0.04 . The comparatively high DMFT value of 0.19 found in 2000 by Pistorius et al. may result of the dental probing that also lead to a caries diagnose in first molars with deep fissures that were not sealed at the time of the examination. Since caries is a process that needs a longer period of time until clinical manifestation, it is hardly surprising that the DMFT was very low. It would have been interesting to know the amount of erupted permanent teeth in this population.

In an international comparison, $\mathrm{dmft}$ and caries experience in our findings were at a low level. Table 3 gives an overview of the available results published in comparable studies within the recent years. However, this is to state with the limitation that most of the studies were conducted in developing countries or structurally weak areas.

Regarding the reasons for the ongoing decrease of the $\mathrm{dmft}$, it is, by nature, difficult to pinpoint the exact causes. The systematic educational work in schools and kindergartens might be a reason for the children's caries decline. In that context, school and preschool children are taught about brushing methods, professional prophylaxis at the dentist's office, the use of fluorides and tooth-protective nutrition. Parental habits, knowledge and attitude play a distinct role for the child's caries prognosis [14]. Possibly, today's six-year-olds profit from the educational work in their parent's childhood and adolescence. In Germany, the market share of fluoridated salt rose from $20 \%$ in 1997 to just below $70 \%$ since 2007. As salt is a simple and effective prevention method, this could be another cause for the caries decrease [15].

Even though childhood caries underwent an enormous reduction within the last years, this fact should not be taken for granted, since numerous studies show a connection between children's socioeconomic status and caries risk [16]. Research on the reasons for the intraoral caries polarisation would be of interest and might lead to therapeutic consequences in future prophylaxis and treatment of deciduous teeth.

\section{Conclusions}

The trend towards lower caries prevalence in RhinelandPalatinate continues. Male first graders have significantly more caries experience than their female schoolmates, both in the fraction with low and the one with high caries activity. Prophylaxis efforts should specially focus on the primary molars, since the $\mathrm{d} 3 \mathrm{mft}$ values were remarkably higher in this area.

Table 3 Overview on other recent studies with 6-year-old children

\begin{tabular}{lllll}
\hline Name & Country & Sample size & Mean dmft & Caries experience(\%) \\
\hline Rajab [17] & Jordan & 2496 & 3.3 & 76.4 \\
Prasaj Dixit [18] & Nepal(Chitwan) & n.a. & 1.59 & 52.0 \\
Hashim [19] & UAE(Ajman) & 429 & 1.12 & n.a. \\
Tadakamadla [20] & India(Udaipur) & 875 & 1.69 & 58.9 \\
Liu [21] & China(Sechuan) & 714 & 3.94 & 74.37 \\
Basha [22] & India(Davangere) & 196 & 3.2 & 50.51 \\
Gorbatova [23] & Russia (Archangelsk) & 532 & 6.71 & 93.4 \\
\hline
\end{tabular}




\section{Competing interests}

The authors declare that they have no competing interests.

\section{Authors' contributions}

JW conceived of the study, collected the data and drafted the manuscript. Statistical analysis was performed by KK, as well as the data digitalisation. AA, $\mathrm{BM}, \mathrm{CW}$ and BW participated in design and coordination and helped to draft the manuscript. All authors read and approved the final manuscript.

\section{Acknowledgements}

The examination sheets were provided by the Landesarbeitsgemeinschaft Jugendzahnpflege Rheinland-Pfalz. The authors thank Mrs. Dufanal and SR Dr. Stein for the good cooperation. Furthermore, we thank Dr. Veronika Weyer for her support in statistical questions.

\section{Author details}

${ }^{1}$ Department of Operative Dentistry, University Medical Center of the, Johannes Gutenberg-University Mainz, Augustusplatz 2, 55131 Mainz, Germany. ${ }^{2}$ Department of Oral and Maxillofacial Surgery, Johannes Gutenberg-University, Mainz, Germany.

Received: 21 April 2015 Accepted: 24 September 2015

Published online: 02 October 2015

\section{References}

1. Marsh PD. Microbial ecology of dental plaque and its significance in health and disease. Adv Dent Res. 1994;8(2):263-71.

2. US Department of Health and Human Services: Oral Health in America: A Report of the Surgeon General. [http://www.nidcr.nih.gov/DataStatistics/ SurgeonGeneral/sgr/chap4.htm]. Access Date 03-23-15.

3. Hobdell M, Petersen PE, Clarkson J, Johnson N. Global goals for oral health 2020. Int Dent J. 2003;53(5):285-8.

4. Ziller S, Micheelis W, Oesterreich D, Reich E. Goals for oral health in Germany 2020. Int Dent J. 2006;56(1):29-32.

5. Thomson WM, Poulton R, Milne BJ, Caspi A, Broughton JR, Ayers KM. Socioeconomic inequalities in oral health in childhood and adulthood in a birth cohort. Community Dent Oral Epidemiol. 2004;32(5):345-53.

6. Anonymous. Oral health: prevention is key. Lancet. 2009, 373(9657):1.

7. Epidemiologische Begleituntersuchung zur Gruppenprophylaxe 2009. DAJ (Deutsche Arbeitsagentur für Jugendzahnpflege). [http://www.daj.de/ fileadmin/user_upload/PDF_Downloads/Studie_Korrektur.pdf]. Access Date 03-23-15.

8. Broadbent JM, Thomson WM. For debate: problems with the DMF index pertinent to dental caries data analysis. Community Dent Oral Epidemiol. 2005;33(6):400-9.

9. Bratthall D. Introducing the Significant Caries Index together with a proposal for a new global oral health goal for 12-year-olds. Int Dent J. 2000;50(6):378-84.

10. Bucher K, Metz I, Pitchika V, Hickel R, Kuhnisch J. Survival characteristics of composite restorations in primary teeth. Clin Oral Investig. 2015;19(7):165362. doi: 10.1007/s00784014-1398-9. Epub 2014 Dec 31.

11. Almerich-Silla JM, Boronat-Ferrer T, Montiel-Company JM, Iranzo-Cortes JE. Caries prevalence in children from Valencia (Spain) using ICDAS II criteria, 2010. Med Oral Patol Oral Cir Bucal. 2014;19(6):e574-580.

12. Schwendicke F, Doost F, Hopfenmuller W, Meyer-Lueckel H, Paris S. Dental caries, fluorosis, and oral health behavior of children from Herat, Afghanistan. Community Dent Oral Epidemiol. 2015. doi: 10.1111/cdoe.12177

13. Pistorius A, Frey S, Krahwinkel T, Willershausen B. Review of existing prophylaxis programs for 3880 first graders from Rhineland Palatinate, Germany. Eur J Med Res. 2003;8(2):85-90.

14. Hooley M, Skouteris H, Boganin C, Satur J, Kilpatrick N. Parental influence and the development of dental caries in children aged 0-6 years: a systematic review of the literature. J Dent. 2012;40(11):873-85.

15. Marthaler TM. Salt fluoridation and oral health. Acta Med Academica. 2013;42(2):140-55.

16. Schwendicke F, Dorfer CE, Schlattmann P, Page LF, Thomson WM, Paris S. Socioeconomic inequality and caries: a systematic review and meta-analysis. J Dent Res. 2015;94(1):10-8.
17. Rajab LD, Petersen PE, Baqain Z, Bakaeen G. Oral health status among 6and 12-year-old Jordanian schoolchildren. Oral Health Prev Dent. 2014;12(2):99-107.

18. Prasai Dixit L, Shakya A, Shrestha M, Shrestha A. Dental caries prevalence, oral health knowledge and practice among indigenous Chepang school children of Nepal. BMC Oral Health. 2013;13:20.

19. Hashim R, Williams S, Thomson WM. Oral hygiene and dental caries in 5- to 6-year-old children in Ajman, United Arab Emirates. Int J Dent Hyg. 2013;11(3):208-15.

20. Tadakamadla SK, Tadakamadla J, Tibdewal H, Duraiswamy P, Kulkarni S Dental caries in relation to socio-behavioral factors of 6-year-old school children of Udaipur district, India. Dent Res J. 2012;9(6):681-7.

21. Liu J, Li X, Hu D, Zhang X, He S. [Caries status of primary and permanent teeth among 6-year-old children in Sichuan province and their correlation]. Hua Xi Kou Qiang Yi Xue Za Zhi. 2012;30(2):214-6. 220.

22. Basha S, Swamy HS. Dental caries experience, tooth surface distribution and associated factors in 6- and 13-year- old school children from Davangere, India. J Clin Exp Dent. 2012;4(4):e210-216.

23. Gorbatova MA, Gorbatova LN, Pastbin MU, Grjibovski AM. Urban-rural differences in dental caries experience among 6-year-old children in the Russian north. Rural Remote Health. 2012;12:1999.

\section{Submit your next manuscript to BioMed Central and take full advantage of:}

- Convenient online submission

- Thorough peer review

- No space constraints or color figure charges

- Immediate publication on acceptance

- Inclusion in PubMed, CAS, Scopus and Google Scholar

- Research which is freely available for redistribution

Submit your manuscript at www.biomedcentral.com/submit
C) Biomed Central 